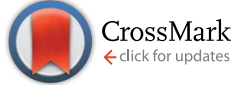

Cite this: RSC Adv., 2017, 7, 5533

Received 18th October 2016 Accepted 27th December 2016

DOI: 10.1039/c6ra25441a

www.rsc.org/advances

\title{
Enhancement in graphitization of coal tar pitch by functionalized carbon nanotubes
}

\author{
H. F. Arani, ${ }^{\text {ab }}$ A. R. Mirhabibi, ${ }^{\text {tbc }}$ S. Collins, ${ }^{c}$ R. Daroughegi, ${ }^{d}$ A. Khalife Soltani, ${ }^{e}$

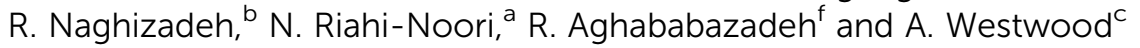

In this study, the influence of the addition of carbon nanotubes (CNTs) and carbon black (CB) on the graphitization temperature and microstructure of coal tar pitch (CTP) are investigated. X-ray diffraction patterns of carbon residues indicate that minimum interlayer spacing $\left(d_{002}\right)$ values are obtained at $2000{ }^{\circ} \mathrm{C}$ for CTP/CNT. Moreover, the Raman spectrum of CTP/CNTs is similar to graphite, and the relative intensity of Raman lines shows that CTP/CB is less graphitized at $2000{ }^{\circ} \mathrm{C}$. In addition, scanning electron microscopy images show that when $\mathrm{CB}$ is added sample textures tend to disordered morphologies. However, CNTs, not only improve the morphology of CTP, but also act as nuclei for the growth of graphite flaky crystallites. The role of the CTP/CNT interface and the defects of CNTs on the graphitization degree are studied using transmission electron microscopy, and a mechanism for the graphitization of CTP, in the presence of CNTs, is proposed.

\section{Introduction}

Coal-tar pitch (CTP) is the solid residue remaining after the distillation of coal, and it is widely used in the molded graphite industry. ${ }^{1,2}$ CTP does not have a defined melting temperature but shows a wide range in softening temperature. Chemically, it consists of a complex matrix, containing numerous aromatichydrocarbon and heterocyclic compounds. CTP is an excellent binding material and a valuable material in the manufacture of carbon-carbon composites, carbon artifacts and synthetic graphite. ${ }^{3}$ The key features that make CTP useful in the carbon industry are high carbon content, the presence of only trace amounts of inorganic compounds in its composition and its capability to graphitize. ${ }^{4}$

Graphite precursors can be divided into two major classes: aromatic hydrocarbons and polymers, each with different carbonization characteristics. ${ }^{5}$ There has been a great effort to synthesize graphite at as low a temperature as possible by using various additives, which consist of two main classes. ${ }^{6-9}$ Much research has been done to enhance the properties of CTP by additives, and many investigators have reported treatment procedures that improve the carbonization behavior of CTP. ${ }^{\mathbf{1 0 - 1 4}}$

${ }^{a}$ Non-Metallic Materials Group, Chemistry and Materials Division, Niroo Research Institute, Tehran, Iran.E-mail: hfallah@nri.ac.ir

${ }^{b}$ School of Materials, Iran University of Science and Technology, Tehran, Iran. E-mail: ar_mirhabibi@iust.ac.ir

'Institute for Materials Research, Leeds University, UK

${ }^{d}$ Department of Chemical Engineering, Faculty of Engineering, University of Kashan, Kashan, Iran

${ }^{e}$ Composite Materials and Technology, Tehran, Iran

Institute for Color Science and Technology (ICST), Iran
However, very little information is available about the effect of additives on the graphitization of CTP.

In this research work, the use of nano carbon additives to promote graphitization of carbon substrate is reported. It seems carbon nano materials such as carbon black (CB) and carbon nanotubes (CNTs) are good candidates as the graphitization agent. CB increases $\alpha$-resin content, carbon yield and enhances the volatile release of pitches. Furthermore, CB decreases resultant coke porosity. ${ }^{15} \mathrm{An}$ interesting property of the CNTs is that they consist of graphene which more surface ordering layers. Incorporation of CNTs in a carbon matrix resulted in a significant change in mechanical, electrical and thermal properties of carbon matrices. ${ }^{16-20}$ Various factors that influence property modification, are processing techniques, type of CNTs, aspect ratio and CNTs content. However, the nature of interactions between pitch components and carbon nano material during carbonizations has not been clarified. ${ }^{18,21-25}$

In the present work, the influences of the addition of CNTs and CB on the graphitization of CTP are studied in detail. The aim of our research was to characterize the influence of CNTs and CB additions on the graphitization degree of CTP. The effect of CNTs on the formation of graphite is also compared with CB. The results were obtained X-ray diffraction (XRD), Raman spectroscopy, scanning electron microscopy (SEM) and transmission electron microscopy (TEM) confirm the formation of flaky graphite crystals.

\section{Experimental}

\section{Materials}

The typical coal tar pitch (AP63) of the Esfahan Pitch Refinery Company (Esfahan, Iran), was utilized as the source of carbon 
(C, 52\%; softening point, $110-120{ }^{\circ} \mathrm{C}$; TI, 29\%). The multi-wall carbon nanotubes (CNTs) (Nanocyl S.A, Belgium) with an average diameter of about $100 \mathrm{~nm}$, length of 0.1-1000 nm, and carbon purity $>95 \mathrm{wt} \%$ and carbon black (CB), with particle size of 25-85 nm, and surface area of 75-95 $\mathrm{m}^{2} \mathrm{~g}^{-1}$ were used as additives in this study.

\section{Preparation of samples}

The multi-walled carbon nanotubes are modified by $\mathrm{HCl}$ and then acid treated with a mixture of $\mathrm{H}_{2} \mathrm{SO}_{4}$ and $\mathrm{HNO}_{3}$ by sonication for 20 hours, finally cleaned by washing and drying.

A series of coal tar pitch solutions in toluene were prepared, by dissolving known quantities of coal tar pitch powder, in $50 \mathrm{ml}$ toluene. Then the acid treated CNTs and CB are dispersed in solution by ultrasonication with $1 \%$ wt and $3 \%$ wt. Samples were dried at room temperature then heated to $1000{ }^{\circ} \mathrm{C}$ with a heating rate of $5{ }^{\circ} \mathrm{C} \mathrm{min}^{-1}$ and kept at the temperature for 5$10 \mathrm{~h}$ in a flow of high-purity Ar gas with a flow rate of $40 \mathrm{ml}$ $\min ^{-1}$. An increase in carbonization yield and chlorine removal were observed at $1000{ }^{\circ} \mathrm{C}$. The product of this heat-treatment was heated to $2000{ }^{\circ} \mathrm{C}$ because at this temperature the initial graphitic structures are gradually revealed. The samples were examined at a lower temperature to reveal the possible graphitic structures formation.

\section{Characterization and measurements}

Raman patterns of carbon residues received from the CTP, CTP/ CB and CTP/CNTs samples at both $1000{ }^{\circ} \mathrm{C}$ and $2000{ }^{\circ} \mathrm{C}$ were obtained. Raman spectroscopy and X-ray diffraction were used for the determination of changes in graphitic structure. Morphology of microstructures studies with scanning electron microscopy (SEM) and transmission electron microscopy (TEM).

XRD measurements were acquired at room temperature using $\mathrm{Cu}-\mathrm{K} \alpha$ radiation source radiation $(\lambda=1.5418 \AA)$ in the range $2 \theta=15-65$ degree at a scanning speed of $3^{\circ} \mathrm{min}^{-1}$. The crystallite size $\left(L_{\mathrm{c}}\right)$ of the (002) plane was computed using the Scherrer equation:

$$
L_{\mathrm{c}} \text { or } L_{\mathrm{a}}=k \lambda / b \cos \theta
$$

where $b$ is the peak width at half maximum height, $\theta$ is the Bragg angle, $\lambda$ is the $\mathrm{X}$-ray wavelength, $k$ is the Scherrer constant and for the (002) peak is 0.9 , while $L_{\mathrm{a}}$ is the crystalline width in the (100) planes and for the (100) peak is 1.84. In XRD patterns of this study, the (100) peak is not clear. Therefore $L_{\mathrm{a}}$ was computed by Raman spectra using the formula: ${ }^{26-28}$

$$
L_{\mathrm{a}}=\left(2.4 \times 10^{-10}\right) \lambda_{\text {laser }}^{4}\left(I_{\mathrm{D}} / I_{\mathrm{G}}\right)^{-1}
$$

$I_{\mathrm{D}}$ and $I_{\mathrm{G}}$ are explained in Raman part. Raman spectroscopy was also applied to further investigate the structural change with a laser source $\operatorname{Ar}^{+}(\lambda=785 \mathrm{~nm}, 50 \mathrm{~mW}$, lateral resolution: $2 \mu \mathrm{m})$. The morphological changes of heat treated CTP was observed by SEM using a Jeol microscope. Graphitizability was computed according to Maire and Mering equation. ${ }^{9}$ The structural changes of heat treated CTP were studied by transmission electron microscopy (TEM). TEM was performed in bright- and dark-field modes using a Philips EM400 microscope.

\section{Results and discussion}

XRD patterns of carbon residues obtained from CTP, CTP/CB and CTP/CNTs at 1000 and $2000{ }^{\circ} \mathrm{C}$ are shown in Fig. 1, and the results are summarized in Table 1 . The maximum $d_{002^{-}}$ values are at $1000{ }^{\circ} \mathrm{C}$ for $\mathrm{CTP} / \mathrm{CB}$ sample. After heat treatment to $2000{ }^{\circ} \mathrm{C}$ the degree of graphitization increased for all samples. However, CTP/CNTs at $2000{ }^{\circ} \mathrm{C}$ show a higher degree of graphitization than $\mathrm{CTP} / \mathrm{CB}$ showing that $\mathrm{CB}$ does not have a positive influence on the graphitization, but CNTs increase the degree of graphitization. Therefore, CNTs improve the formation of flaky graphite crystals. ${ }^{29}$ It is significant to note that for all samples, the degree of graphitization increased with temperature and that CTP samples at $1000{ }^{\circ} \mathrm{C}$ are less graphitized than sample at $2000{ }^{\circ} \mathrm{C}$. Therefore, the temperature is the essential factor for graphitization.

Fig. 1 shows the XRD patterns of products heat treated at $1000{ }^{\circ} \mathrm{C}$ for $5 \mathrm{~h}$. The 002 and 100 peaks are remarked in them. As depicted in Fig. 1, two diffraction peaks which are characterized as (002) and (100) dedicated the strongest intensities to themselves; furthermore, they reflect the degree of order normal to the graphene sheets. The peak which is specified as (100) demonstrates the order within the graphene plane. The stacking order of graphene sheets in three-dimensions can be achieved from the width of the (101) and (110) peaks. The main reason of weakness of the (100) peak is due to the fact that the carbon atoms are joined by the strong covalent bonding in a graphene sheet. ${ }^{30-32}$ In addition, it is clear that CTP coke has an amorphous structure at $1000{ }^{\circ} \mathrm{C}$ by the position and width of the X-ray diffraction peaks. Fig. 2 displays the XRD patterns for $\mathrm{CTP}, \mathrm{CTP} / \mathrm{CNT}$ and $\mathrm{CTP} / \mathrm{CB}$ at $2000{ }^{\circ} \mathrm{C}$. As the heating temperature increases to $2000{ }^{\circ} \mathrm{C}$, significant changes occur such as the formation of some new peaks (101 and 004), and also the (002) peak becomes very sharp. This behavior with increasing temperature has already been observed by other researchers. ${ }^{33-35}$

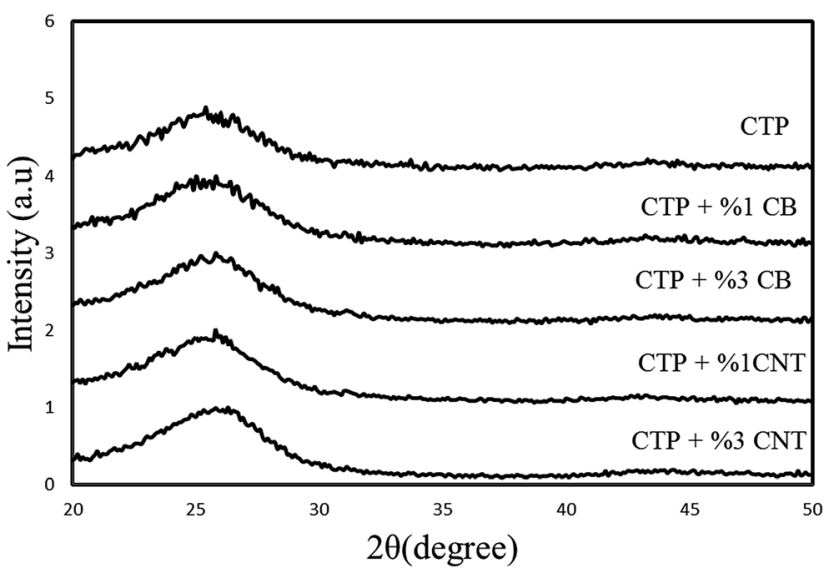

Fig. 1 XRD patterns of carbon residues obtained from a mixture of CTP with CNT and CB at $1000^{\circ} \mathrm{C}$. 
Table 1 XRD pattern results of coal tar pitch coke ${ }^{a}$

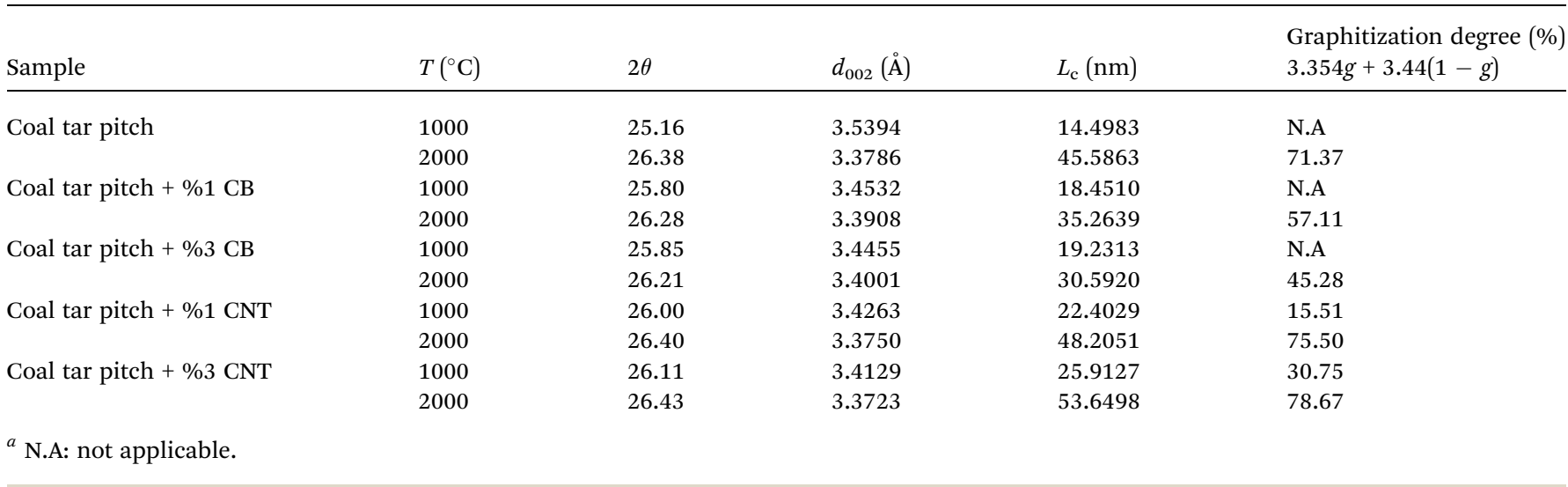

It can be deduced that the in-plane graphitic structure has ameliorated, and this specific structure developed by increasing the temperature. It can be seen that the specific peak (002) has the strongest intensity in all the samples, and that an alteration takes place in (002) peak with a variety of additives. The (002) peak in CTP/CNTs, which was heat treated at $2000{ }^{\circ} \mathrm{C}$ is sharper than the similar peak that was generated in CTP/CB under the same conditions. As the (002) peak becomes sharper, the generation of graphitic structure is going to be better. Therefore, in the CTP coke heat treated at $2000{ }^{\circ} \mathrm{C}$ with CNTs, a strong and narrow (002) peak at $2 \theta=26.43^{\circ}$ was strongly detected and with the addition of $\mathrm{CB}$, the 002 peak broadened and shifted to slightly lower angles around $2 \theta=26.21^{\circ}$. As the $d$-spacing of graphene sheets $\left(d_{002}=3.335 \AA\right)$ increases the degree of graphitization decreases. It is found here that in the heat treated CTP coke with CB at $2000{ }^{\circ} \mathrm{C}$, there are more nongraphitized areas than in CTP/CNTs. Moreover, a slight increase in the amount of $\mathrm{CB}$ additives caused an increase in disorder in the crystal lattice, that was observed by an increase in the width of the 002 peak. ${ }^{36}$

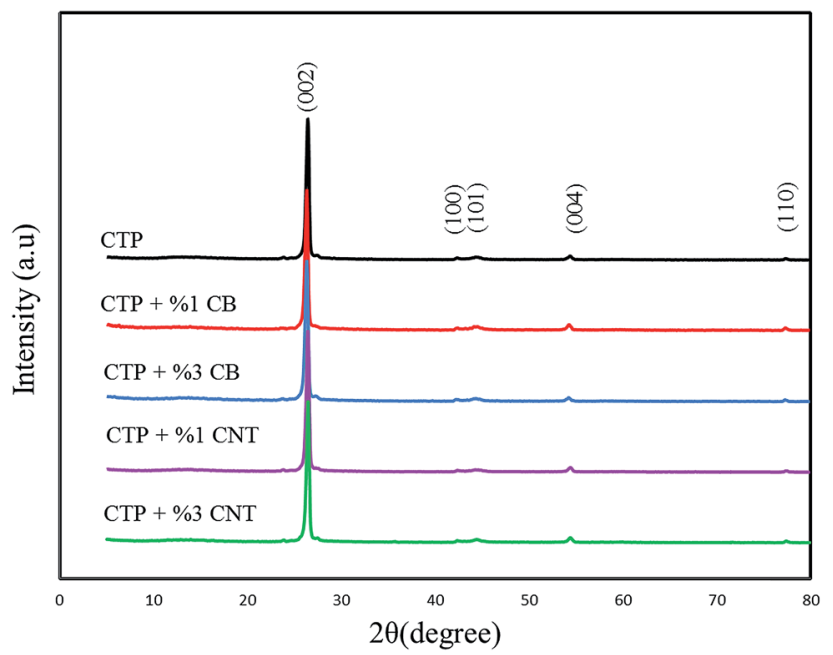

Fig. 2 XRD patterns of carbon residues obtained from a mixture of CTP with CNT and CB at $2000^{\circ} \mathrm{C}$.
The $L_{\mathrm{c}}$ values increase when the temperature reaches $2000{ }^{\circ} \mathrm{C}$ with the largest $L_{\mathrm{c}}$ value being for CTP/CNTs sample. Therefore, at $2000{ }^{\circ} \mathrm{C}$, the crystalline order of CTP/CNTs is higher as and it progresses towards alignment of graphite layers. From this result, it can be seen that either adding CNT or increasing the temperature assists the formation of graphite in CTP. ${ }^{29}$

Raman patterns of carbon residue obtained from CTP/CNTs and CTP/CB at $2000{ }^{\circ} \mathrm{C}$ are shown in Fig. 3. All the graphite samples of single crystal type and the polycrystalline type have the Raman line about $1580 \mathrm{~cm}^{-1}$ and $1360 \mathrm{~cm}^{-1}$, respectively. In Raman spectrum, the G-band corresponds to normal graphite structure, and D-band corresponds to defect or disorder. In addition, the Raman spectrum of graphite has two peaks in 1620 and $2700 \mathrm{~cm}^{-1}$ which are denoted by the $\mathrm{D}^{\prime}$ and $\mathrm{G}^{\prime}$-bands, respectively. ${ }^{37}$

As a matter of fact, two main reasons would cause the intensity of D-band (1360 $\mathrm{cm}^{-1}$ line) to increase. The amount of "unorganized" carbon in the samples has a direct correlation with the intensity of D-band, while the size of graphite crystal decreases the intensity of D-band. The G-band, is actually an aspect that arises from the in-plane stretching of the $\mathrm{C}-\mathrm{C}$ bond

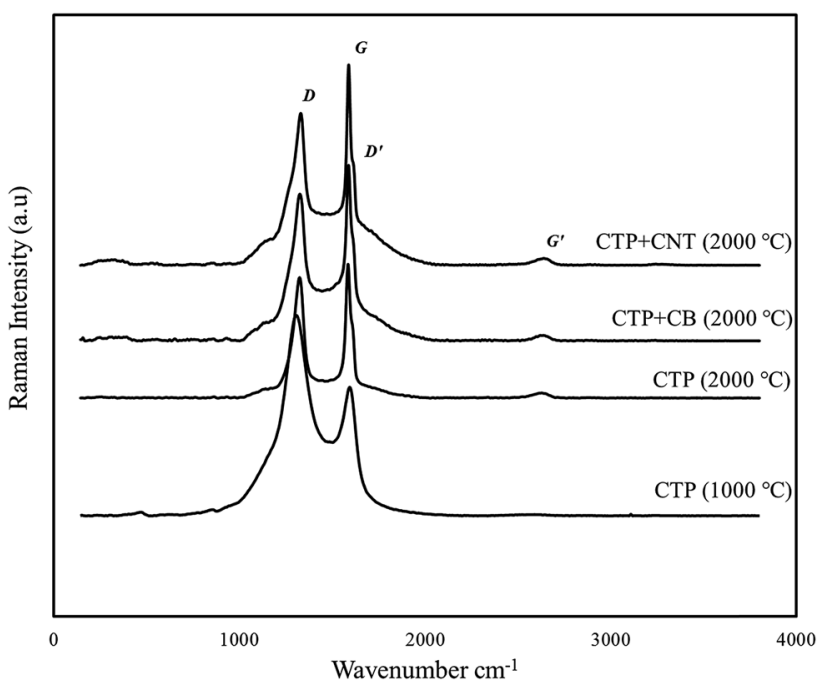

Fig. 3 Raman spectra of coal tar pitch. 
Table 2 Raman spectra parameters

\begin{tabular}{lccr}
\hline Sample & $I_{\mathrm{D}} / I_{\mathrm{G}}$ & $\Delta\left(I_{\mathrm{G}}\right)$ & \multicolumn{1}{c}{$L_{\mathrm{a}}(\mathrm{nm})$} \\
\hline Coal tar pitch & 0.71 & 25.16 & 135.34 \\
Coal tar pitch + \%3 CB & 0.79 & 25.80 & 73.54 \\
Coal tar pitch + \%3 CNT & 0.68 & 25.85 & 143.45 \\
\hline
\end{tabular}

and the $\mathrm{G}^{\prime}$-band exhibit the out-of-plane stacking order of graphite. The ratio of D-band to G-band which has the value of $I_{1360} / I_{1580}$ is actually a crucial factor that is dependent on the graphitization degree and the orientation of the graphite planes. $^{16,38}$

$\Delta(1580)$, the full width at half maximum of the $1580 \mathrm{~cm}^{-1}$ band, is utilized for characterization of graphitic materials as well. In addition, $\Delta(1580)$ shows the degree of graphitization and omits of the disordered layer, and it reduces after heat treatment. As it's obvious from the Raman spectrum of CTP, two strong peaks are detected in the frequency range of $1360 \mathrm{~cm}^{-1}$ (D-band) and $1580 \mathrm{~cm}^{-1}$ (G-band). Increasing the temperature to $2000{ }^{\circ} \mathrm{C}$ not only brings about the generation of $\mathrm{D}$ and $\mathrm{G}$ bands, but also alters the $I_{\mathrm{D}} / I_{\mathrm{G}}$ ratio. By adding CB to CTP, the ratio of the relative intensity of the Raman lines $\left(I_{\mathrm{D}} / I_{\mathrm{G}}\right)$ of CTP, increases from 0.71 to 0.79 , confirm the XRD results.

Although no $\mathrm{G}^{\prime}$ peak, but this specific peak which is a weak broad peak at $2700 \mathrm{~cm}^{-1}$, is seen in samples heated at $1000^{\circ} \mathrm{C}$, it emerged after heating up the sample to $2000{ }^{\circ} \mathrm{C}$. The D-band is observed near the G-band. In the CTP sample which heat treated at $2000{ }^{\circ} \mathrm{C}$, both of the 1580 and $1350 \mathrm{~cm}^{-1}$ bands are sharper more intense in comparison to the samples with $\mathrm{CB}$ additives. Therefore, at $2000^{\circ} \mathrm{C}$, not only the intensity of $\mathrm{G}$ peak is much higher than the corresponding $\mathrm{D}$ peak, but also the $\mathrm{D}^{\prime}$

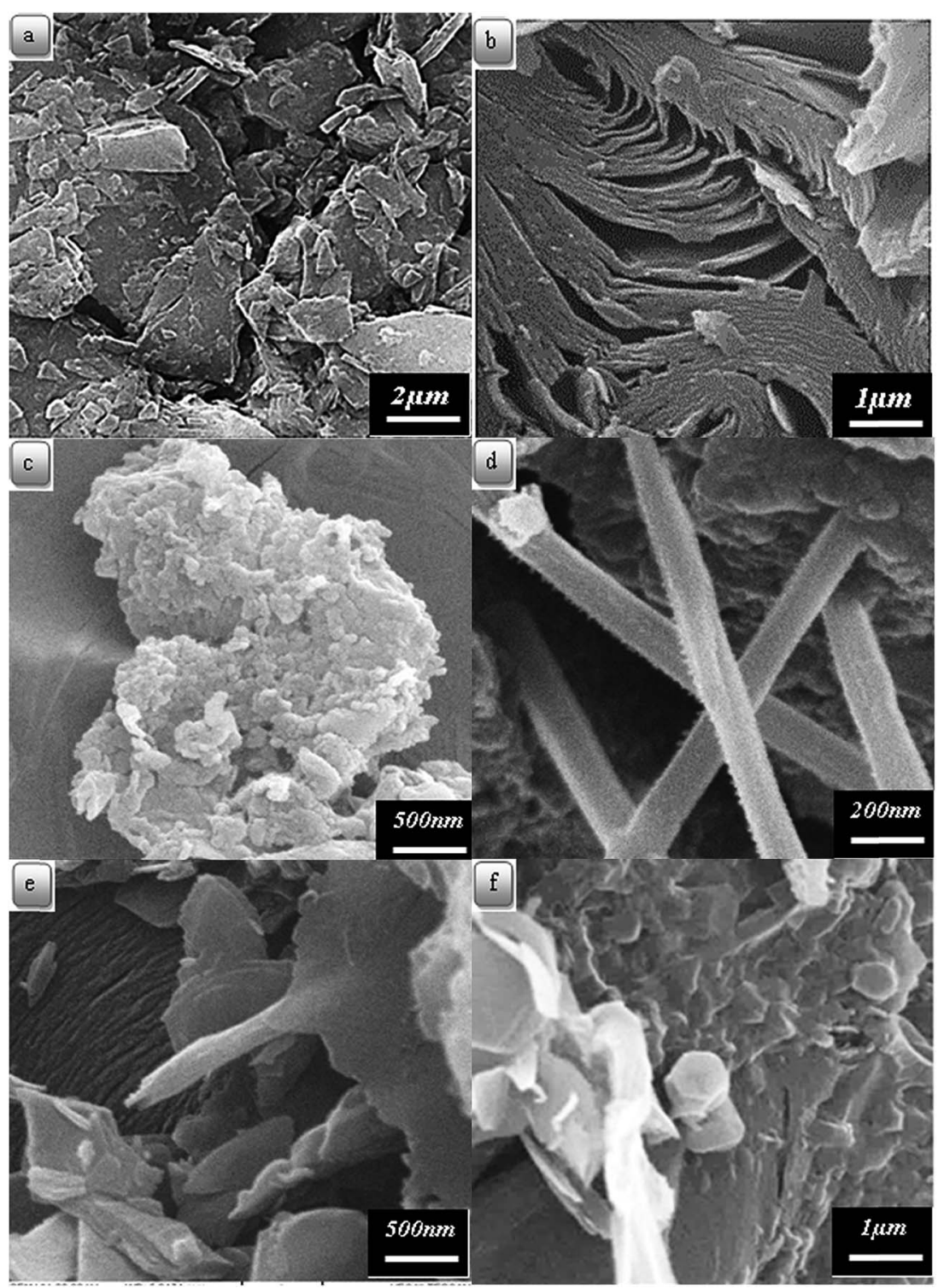

Fig. 4 Scanning electron micrographs of carbon residues obtained from: (a) CTP at $1000^{\circ} \mathrm{C}$; (b) CTP at $2000^{\circ} \mathrm{C}$; (c) CTP with $\mathrm{CB}$ at $2000{ }^{\circ} \mathrm{C}$, (df) CTP with CNT at $2000^{\circ} \mathrm{C}$. 

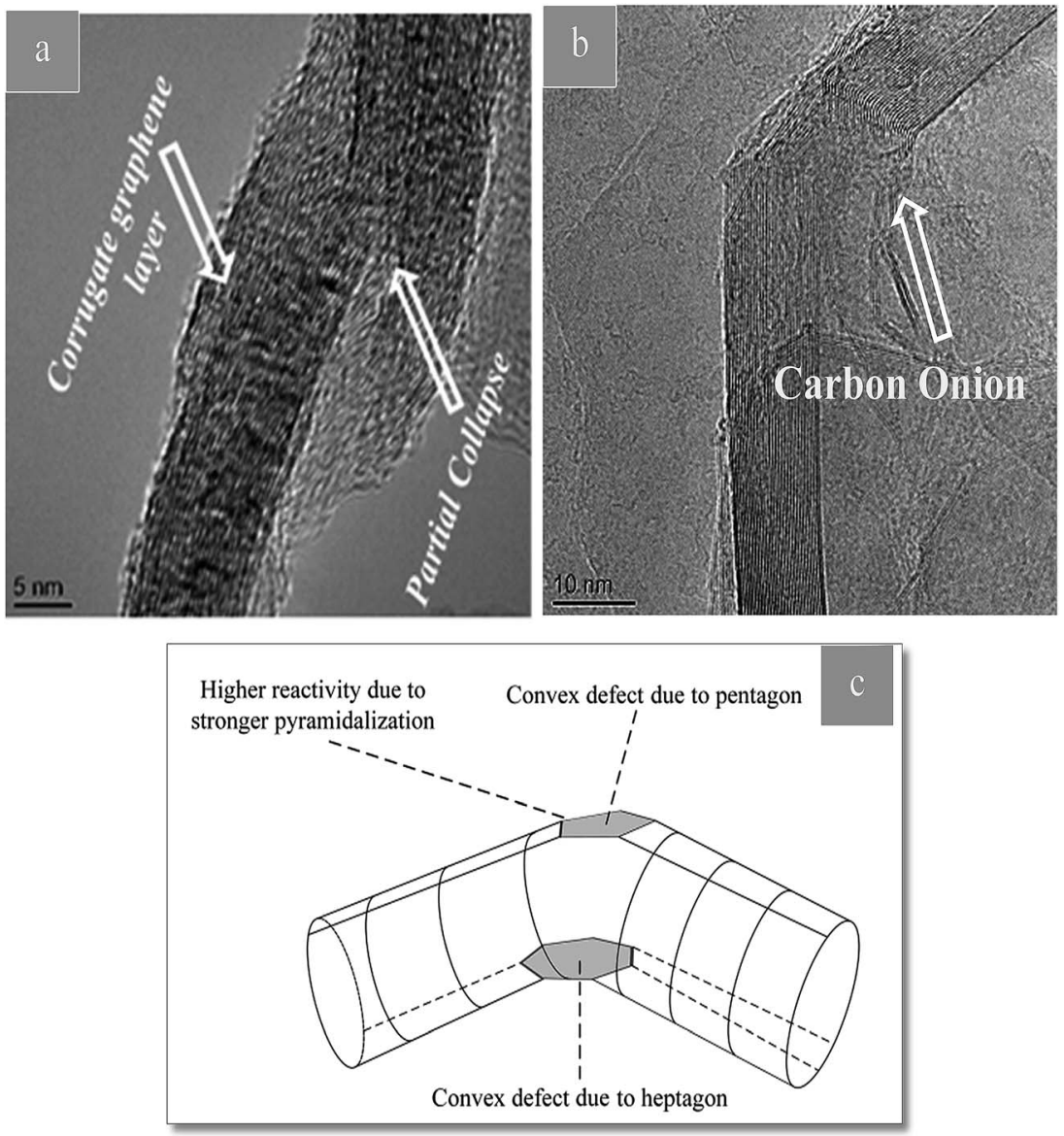

Fig. 5 ( $a$ and b) TEM images of CNT in CTP showing defects induced in CNT. (c) Scheme showing a kink defect. The reactivity of carbon atoms is increased, especially on the convex side.

peak play as the support of the G peak. As the temperature approaches to $2000{ }^{\circ} \mathrm{C}$, the location of CTP is shifted a bit to a slightly lower frequency which is because of an improved alignment of the graphitic structure. The Raman spectrum of CTP/CNTs has sharper peaks than the peaks of CTP/CB and is similar to the Raman spectrum of graphite. ${ }^{39}$ In addition, it can be deduced from the Raman results that CTP/CB is less graphitized at $2000^{\circ} \mathrm{C}$ in comparison to the sample CTP/CNTs. Correspondingly, CNTs additives have a positive effect with respect to the graphitization temperature of CTP.
Raman spectra parameters are shown in Table 2. Based on these data, the $I_{\mathrm{D}} / I_{\mathrm{G}}$ ratio of CTP/CNTs has the lowest value. It is clearly found that, CTP/CNTs has the least disordered structure with improved graphitization. Moreover, the $L_{\mathrm{a}}$ value of this sample has the highest value among the samples. This suggests that CNTs additives improve growth of graphite crystallite.

The surface morphology images of the samples were obtained by SEM. Fig. 4(a)-(f) shows the SEM images of carbon residues obtained from CTP, CTP/CNTs and CTP/CB at 1000

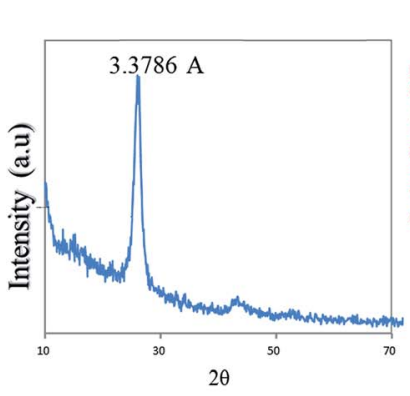

(a)

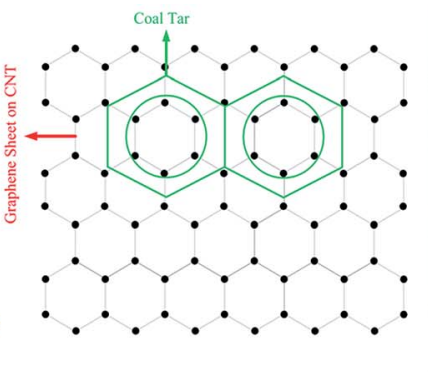

(b)

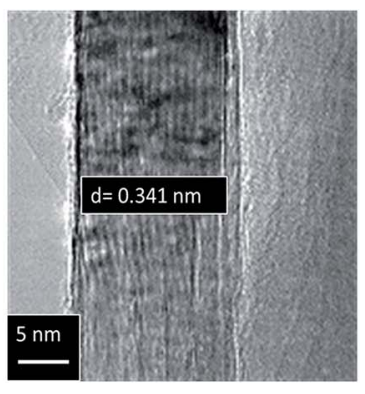

(c)

Fig. 6 (a) 100\% intensity peak in XRD pattern of CTP. (b) Schematic of atomic arrangement at the interface of basal plane of CTP and CNT surface. (c) TEM image of defect-free CNT. 
and $2000{ }^{\circ} \mathrm{C}$. It is obvious from SEM, that CTP has layered microstructure at $1000{ }^{\circ} \mathrm{C}$. It is also seen from Fig. 4(b) that there is layered microstructure and bent microstructure in the CTP coke. The flake size of CTP coke reduces and becomes denser than CTP coke at $1000{ }^{\circ} \mathrm{C}$. After heat-treatment at $2000{ }^{\circ} \mathrm{C}$, the carbon layers of CTP/CNTs tend to be thinner and flatter than CTP/CB (Fig. 4(e)). It should be noted that in CTP/CB (Fig. 4(c)), the surface morphology and layered microstructure or orientation change. By the addition of $\mathrm{CB}$, the texture of samples tends to increase disorder. So, CB can cause disorientation in the CTP matrix and increase space between the layers. Therefore, CB does not seem to have a positive role in lowering the graphitization temperature. ${ }^{40}$

In Fig. 4(d)-(f), the presence of the CNTs is shown. The dispersion of the CNTs in CTP is not uniform. Flaky crystallites are frequently shown next to CNTs rather than in the matrix. So, CNTs seems to have more preferable sites than the matrix for graphitization. ${ }^{\mathbf{4 1}}$

The CTP/additive interface plays a major role in determining the degree of graphitization. CTP crystals form coherent or

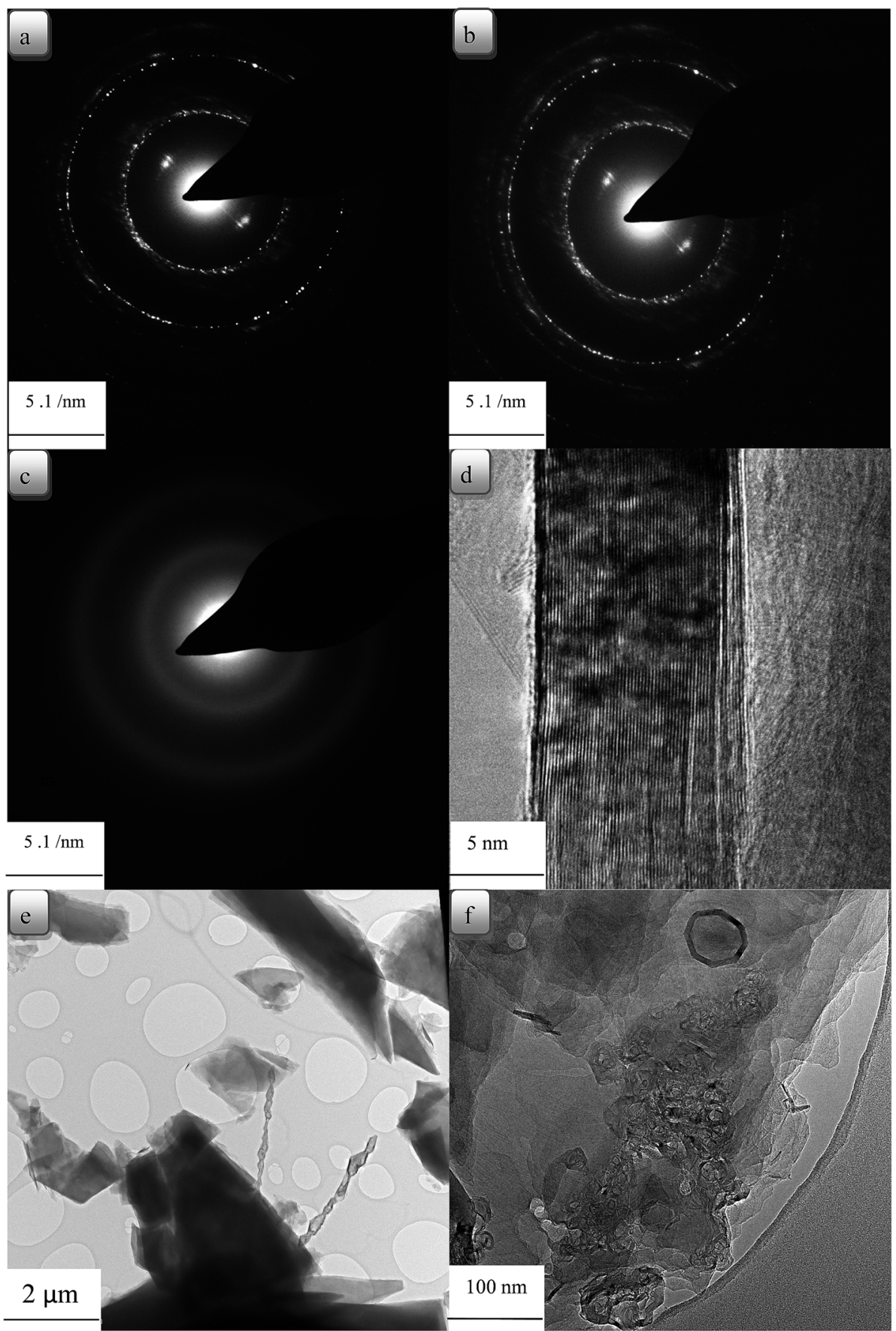

Fig. 7 TEM micrographs of carbon residues at $2000{ }^{\circ} \mathrm{C}$ obtained (a) CTP (b) CTP $+\% 3$ CB (c) CTP $+\% 3$ CNT (d) CTP $+\% 3$ CNT (e) CTP $+\% 1$ CNT (f) $C T P+\% 3 C B$ 
semi-coherent interfaces with the CNTs, resulting in an improvement of the graphitization of the CTP matrix.

CNTs show an inter-wall distance of $0.357 \mathrm{~nm}$, which is slightly higher than defect-free CNTs inter-wall distance of $0.34 \mathrm{~nm}$. CTP matrix may be identified by the lattice spacing of $0.337 \mathrm{~nm}$ for the (002) plane, which produces the $100 \%$ intensity peak in XRD pattern of CTP. The interface becomes incoherent when $\delta>0.25$ but the mismatch $(\delta)$ between CTP and CNTs is lower than $0.25 .{ }^{42}$ Therefore, there is a greater possibility that basal planes of CTP are parallel to the graphene sheet on CNTs wall. There are symmetrical features due to the hexagonal arrangement of C (CNTs) and C (CTP) atoms.

Two various types of interfaces can exist within the CTP/ CNTs system. They are: (i) CTP crystals along the CNTs end (cross-section) and (ii) CTP crystals attached to CNTs wall. Only in the case of a small lattice mismatch $(\delta)$ giving rise to a minimum lattice strain, will a good interfacial bonding be obtained. CTP crystals try to align on the surface of CNTs resulting in minimum atomic distance mismatch. Hence, the basal plane of CTP forms a strong and coherent interfacial bond with the CNTs wall. Thus, basal planes of CTP crystals prefer to align on the CNTs surface. It should be noted that the possible mechanisms for graphitization, favor surface defects. ${ }^{43,44}$

There are a few defects such as pentagons or heptagons that exist on the sidewalls of the nanotubes.

These defects may be, for example, holes in the side wall bearing $\mathrm{sp}^{3}$-hybridized carbon atoms around their rim. The latter may either be saturated with functional groups, or they may exist as "dangling bonds". The reactivity of the respective nanotube is markedly increased at these positions. Fig. 6(c) shows a TEM image of as-received CNTs which is defect-free. The defects in CNTs are observed in Fig. 5. Disturbed arrangement of concentric tubular walls in CNTs with the presence of different types of defects, e.g. carbon onion, kink, partial collapse of nanotube walls and corrugated structure of graphene layers are observed in Fig. $5 .^{45}$

The intensity ratio of $\mathrm{D}$ and $\mathrm{G}$ peaks $\left(I_{\mathrm{D}} / I_{\mathrm{G}}\right)$ is the index of defect density present in CNTs. At defect sites along the sidewalls and tube ends, graphitization probably takes place, and they can easily oxidize in order to generate open tubes. Open ends of CNTs generate a semi coherent interface with CTP crystals. This kind of interface has an orientation such that (002) planes can be parallel to CNTs walls. The key factor in the improvement of the degree of graphitization is the strong and coherent interface between CNTs and CTP without any reaction product.

Specifically, the presence of CNTs, improves the surface morphology and layered microstructure. By increasing the layered microstructure of CTP with the addition of CNTs, it seems that CNTs should be effective in increasing the degree of graphitization. As shown in Fig. 4, by the addition of CNTs, graphite-like particles are presented around the CNTs and they can act as nuclei for further graphitization. It should be emphasized that CNTs increase the amount of graphite-like forms of carbon considerably.

In Fig. 7(a), the diffraction pattern of hexagonal symmetry of CTP coke is shown. Fig. 7(b) shows electron diffraction images of $\mathrm{CTP} / \mathrm{CB}$, and the turbostratic structures are revealed. ${ }^{46}$
Moreover, electron diffraction patterns display a polycrystalline pattern with four rings. The rings demonstrate no preferred orientation of crystallites. The first ring (002), the second (100), the third (004) and the fourth (110) have a $d$-spacing about 3.39 to $3,2.13,1.7$ to 1.4 and $1.23 \AA$, respectively. ${ }^{47}$ In Fig. $7(\mathrm{c})-(\mathrm{e})$ coke resulted from CTP/CNTs heat treated at $2000{ }^{\circ} \mathrm{C}$ with welloriented layers in the graphite crystal are shown. The graphitic structure of the CTP/CNTs is confirmed by analysis of the electron diffraction. This is in good agreement with the XRD data. Flaky morphology of graphite is seen from the bright-field image in Fig. 7(e) and these flakes have a range of sizes. There are graphite layers in some flakes, and they are well oriented. In Fig. 7(e), graphene layers are observed and bilayer and few-layer graphene were found in some images. It also shows graphite layers, extensively exfoliated to give monolayer and multilayer graphene. It can be seen that the graphene sheet edges tend to scroll and fold slightly. As shown in Fig. 7(f), the formation of graphite layers begins from surface layers of $\mathrm{CB}$ particles, which are well known. However, the areas in the CTP/CB coke heat treated at $2000{ }^{\circ} \mathrm{C}$ prove to have disordered structure not the graphitic one.

The aggregate spherical colloidal constituents of about 30$100 \mathrm{~nm}$ in Fig. 7(f) demonstrate that the additives modify the morphology of the matrix. It can be concluded from TEM images that $\mathrm{CTP} / \mathrm{CB}$ has a random structure which also demonstrated a slightly higher $d$-spacing for the (002) reflection.

TEM observations reveal that the CTP/CNT samples have an influence over long range order to produce hexagonal lattice diffraction.

\section{Conclusions}

We report the influences of the addition of CNTs and CB on the degree of graphitization and microstructure of CTP. The excellent formation of graphitic structure in the CTP is mainly attributed to the presence of CNTs, which can act as nuclei for the graphitization of CTP. Furthermore, CNTs can enhance the morphology of CTP through the graphitization process, while the presence of CB results in a disordered morphology. Meanwhile, the strong and coherent interface between CNTs and CTP plays an important role in the improvement of the degree of graphitization of CTP. This research will pave the way to examine the addition of other nano carbons (such as fullerene, graphene, etc.) in order to increase the degree of the graphitization of CTP.

\section{Acknowledgements}

This work was supported by Iran University of Science and Technology (Grant No. 1393) and Niroo Research Institute of Iran (Grant No. 23301).

\section{Notes and references}

1 Y. Zhu, X. Zhao, L. Gao, L. Jun, J. Cheng and S. Lai, J. Mater. Sci., 2016, 51, 8098-8107. 
2 Q. Lin, T. Li, Y. Ji, W. Wang and X. Wang, Fuel, 2005, 84, 177182.

3 A. M. Mastral and M. S. Callén, Environ. Sci. Technol, 2000, 34(15), 3051-3057.

4 I. Mochida, Y. Korai, C. H. Ku, F. Watanabe and Y. Sakai, Carbon, 2000, 38, 305-328.

5 H. O. Pierson, Handbook of Carbon, Graphite, Diamonds and Fullerenes: Processing, Properties and Applications (Materials Science and Process Technology), Noyes, New Mexico, 1993.

6 Y. Wang, J. E. Panzik, B. Kiefer and K. K. M. Lee, Sci. Rep., 2012, 2, 250.

7 T. Brzozowska, J. Zielinski and J. Machnikowski, J. Anal. Appl. Pyrolysis, 1998, 48, 45-58.

8 C. Ren, T. Li, F. Song, X. Sun and Q. Lin, Mater. Lett., 2006, 60, 1570-1574.

9 H. F. Arani and A. Mirhabibi, Fullerenes, Nanotubes, Carbon Nanostruct., 2016, 24, 34-42.

10 Q. Lin, H. Tang, C. Li and L. Wu, J. Anal. Appl. Pyrolysis, 2004, 71, 817-826.

11 M. Dumont, M. A. Dourges, X. Bourrat, R. Pailler, R. Naslain, O. Babot, M. Birot and J. P. Pillot, Carbon, 2005, 43, 22772284.

12 G. Nanosheets, H. Guo, X. Wang, Q. Qian, F. Wang and X. Xia, ACS Nano, 2009, 3, 2653-2659.

13 H. Ujiura and E. Yasuda, Carbon, 1997, 35, 169-174.

14 D. Mikociak, A. Magiera, G. Labojko and S. Blazewicz, J. Anal. Appl. Pyrolysis, 2014, 1-6.

15 S. Wen and D. D. L. Chung, Carbon, 2004, 42, 2393-2397.

16 M. Castillo-Rodríguez, A. Muñoz and A. DomínguezRodríguez, J. Eur. Ceram. Soc., 2016, 36, 2573-2578.

17 B. Milsom, G. Viola, Z. Gao, F. Inam, T. Peijs and M. J. Reece, J. Eur. Ceram. Soc., 2012, 32, 4149-4156.

18 D. H. Nam, S. Il Cha, Y. J. Jeong and S. H. Hong, J. Nanosci. Nanotechnol., 2013, 13, 7365-7369.

19 K. Asaka, M. Karita and Y. Saito, Appl. Phys. Lett., 2011, 91907.

20 T. Maitra, S. Sharma, A. Srivastava and Y. Cho, Carbon, 2011, 50, 1753-1761.

21 A. Bianco, K. Kostarelos and M. Prato, Curr. Opin. Chem. Biol., 2005, 9, 674-679.

22 J. Bermejo and V. Cebolla, Carbon, 1996, 34, 895-902.

23 K. Kanno, K. Eui Yoon, J. J. Fernandez, I. Mochida, F. Fortin and Y. Korai, Carbon, 1994, 32, 801-807.

24 N. Jeong, K. S. Hwang, S. Yang and S. P. Lee, Mater. Charact., 2014, 89, 69-80.

25 A. R. Boccaccini, J. Cho, T. Subhani, C. Kaya and F. Kaya, J. Eur. Ceram. Soc., 2010, 30, 1115-1129.
26 C. Czosnek and W. Ratuszek, Fuel Process. Technol., 2002, 79, 199-206.

27 G. Sodeifian, R. Daroughegi and J. Aalaie, Korean J. Chem. Eng., 2015, 32, 1-8.

28 S. Masudy-Panah, R. S. Moakhar, C. S. Chua, A. Kushwaha, T. I. Wong and G. K. Dalapati, RSC Adv., 2016, 6, 2938329390.

29 N. Iwashita, C. Rae and H. Fujimoto, Carbon, 2004, 42, 701714.

30 M. Kawasaki, K. Sompetch, T. Sarakonsri and M. Shiojiri, Mater. Charact., 2015, 110, 60-67.

31 S. Farhan, R. Wang and K. Li, J. Mater. Sci., 2016, 51, 79918004.

32 H. Xue, T. Wang, H. Guo, X. Fan, Z. Zhu, X. Pan and J. He, RSC Adv., 2014, 4, 57724-57732.

33 A. R. Kamali, C. Schwandt and D. J. Fray, Mater. Charact., 2011, 62, 987-994.

34 H. Liu, J. Huang, X. Li, J. Liu and Y. Zhang, Ceram. Int., 2012, 38, 5145-5149.

35 A. V Talyzin, I. De, F. Langenhorst, P. S. Sokolov and V. L. Solozhenko, J. Phys. Chem. C, 2009, 113, 11279-11284.

36 S. Jae, J. Choe, Y. Jin, S. Lim, K. Lee, Y. Seung, S. Choi, S. Park, Y. S. Hwang, G. Kim and C. Rae, Fusion Eng. Des., 2012, 87, 344-351.

37 H. Zhu, Y. Cao, J. Zhang, W. Zhang, Y. Xu, J. Guo, W. Yang and J. Liu, J. Mater. Sci., 2016, 51, 3675-3683.

38 B. Wu, C. Wang, Y. Cui, L. Mao and S. Xiong, RSC Adv., 2015, 5, 16986-16992.

39 P. Zhai, J. Liu, J. Zeng, J. Duan, L. Xu, H. Yao, H. Guo, S. Zhang, M. Hou and Y. Sun, Carbon, 2016, 101, 22-27.

40 M. R. Delport and H. Badenhorst, J. Mater. Sci., 2016, 51, 6309-6318.

41 R. Zhang and R. Tang, J. Mater. Sci., 2016, 51, 5802-5810.

42 D. A. Porter, K. E. Easterling and M. Sherif, Phase Transformations in Metals and Alloys (Revised Reprint), CRC press, 2009, vol. 53.

43 L. Ci, Z. Ryu, N. Y. Jin-Phillipp and M. Rühle, Acta Mater., 2006, 54, 5367-5375.

44 C. S. Goh, J. Wei, L. C. Lee and M. Gupta, Nanotechnology, 2005, 17, 7 .

45 D. Lahiri, V. Singh, A. K. Keshri, S. Seal and A. Agarwal, Carbon, 2010, 48, 3103-3120.

46 Z. Q. Li, C. J. Lu, Z. P. Xia, Y. Zhou and Z. Luo, Carbon, 2007, 45, 1686-1695.

47 C. Chen, Y. Dai, J. Gwo and J. Jehng, Carbon, 2006, 44, 18081820. 